ISSN 1981-416X

Licenciado sob uma Licença Creative Commons

(c) (1)

\title{
Conselhos municipais de educação: participação, qualidade e gestão democrática como objeto de recorrência
}

Municipal councils of education: participation, quality and democratic management as object of recurrence

Consejos municipales de educación: participación, calidad y gestión democrática como objeto de recurrencia

\section{Paulo Gomes Lima, Gilsemara Vasques Rodrigues Almenara, Jociane Marthendal Oliveira Santos*}

Universidade Federal de São Carlos, Campus Sorocaba, Sorocaba, SP, Brasil

\section{Resumo}

A presente pesquisa tem como objetivo discutir o papel dos Conselhos Municipais de Educação quanto à autonomia, à participação, à qualidade e à construção da consciência coletiva no processo de gestão democrática. A metodologia utilizada, de cunho qualitativo, recorre de forma compreensiva às interlocuções com o objeto. Trata-se de uma pesquisa exploratória, por meio de revisão de literatura especializada. Nesse trabalho autores como

*PGL: Doutor em Educação, e-mail: paulolima@ufscar.br GVRA: Graduada em Pedagogia, e-mail: gil.sedu@gmail.com JMOS: Graduada em Psicologia, e-mail: jmarthendal@yahoo.com.br 
Cury (2002; 2004; 2006), Bordignon (2009; 2010), Lima (2013), Gohn (2002; 2006; 2007) e Vasconcelos (2003) dentre outros, apresentam uma discussão aprofundada acerca dos Conselhos Municipais de Educação sobre a força, a mobilização social e a participação como eixos transversais necessários às mudanças sociais. A pesquisa explicita que os canais de legitimação instituídos são pontos de partida para a dimensão mais ampla e necessária do instituinte, ou seja, do papel efetivo dos conselheiros e sociedade em constante recorrência para o estabelecimento de suas expectativas quanto a educação desejada, as transformações necessárias, a constituição de políticas democratizadoras e a abertura ao diálogo.

Palavras-chave: Conselhos Municipais de Educação. Consciência coletiva. Participação. Qualidade. Gestão democrática.

\section{Abstract}

The present research aims to discuss the role of the Municipal Councils of Education regarding autonomy, participation, quality and the construction of collective consciousness in the process of democratic management. The qualitative methodology used allows the interlocutions with the object. This is an exploratory research, conducted through literature review. In this work authors such as Cury (2002; 2004; 2006), Bordignon (2009; 2010); Lima (2013), Gohn (2002; 2006; 2007) and Vasconcelos (2003), among others, present an in-depth discussion of the Municipal Education Councils on strength, social mobilization and participation as transversal axes necessary for social change. The research explicitly states that the channels of instituting legitimation are starting points for the broader and more necessary dimension of the institute, that is, the effective role of counselors and society in constant recurrence to establish their expectations regarding the desired education, the necessary transformations, the constitution of democratizing policies and the opening to the dialogue.

Keywords: Municipal councils of education. Collective consciousness. Participation. Quality. Democratic management. 


\section{Resumen}

La presente investigación tiene como objetivo discutir el papel de los Consejos Municipales de Educación como la autonomía, participación, calidad y la construcción de la conciencia colectiva en el proceso de gestión democrática. La metodología utilizada de cuño cualitativo recurre de forma comprensiva a las interlocuciones con el objeto. Se trata de una investigación exploratoria, por medio de revisión de literatura especializada. En ese trabajo autores como Cury (2002; 2004; 2006), Bordignon (2009; 2010), Lima (2013), (2002; 2006; 2007) y Vasconcelos (2003) entre otros, presentan una discusión en profundidad de los Consejos Municipales de Educación sobre la fuerza, la movilización social y la participación como ejes transversales necesarios a los cambios sociales. La investigación explicita que los canales de legitimación instituidos son puntos de partida para la dimensión más amplia y necesaria del instituyente, o sea, del papel efectivo de los consejeros y sociedad en constante recurrencia para el establecimiento de sus expectativas en cuanto a la educación deseada, las transformaciones necesarias, la constitución de políticas democratizadoras y la apertura al diálogo.

Palabras clave: Consejos municipales de educación. Consciencia colectiva. Participación. Calidad. Gestión democrática.

\section{Introdução}

Os Conselhos Municipais de Educação são considerados espaços legítimos de gestão democrática na política educacional. O debate a respeito de conselhos municipais de educação, das últimas décadas no Brasil, manifesta-se frequentemente por meio de movimentos com o objetivo de superar a herança colonial da centralização de poder, das decisões que desconsideram a capacidade da comunidade local para gerir seus caminhos. Contra o centralismo das decisões sobre a vida da municipalidade, sabe-se que a própria vida social de uma determinada região ou município estará muito mais pronta para conduzir e resolver suas próprias demandas do que intenções e assertivas de políticas top-down. 
Constituído por uma assembleia de pessoas, o conselho como colegiado que privilegia a participação popular tem e deve ter natureza pública, para proceder de forma a aconselhar, emitir parecer, deliberar com relação a questões de interesse público em sentido amplo ou restrito. Dessa forma um Conselho deve ser representado por meio de pluralidades, expressando as expectativas e vozes do grupo social. Estas manifestações ocorrem inicialmente por meio de assembleias legitimadas, e posteriormente por normas escritas sobre assuntos de interesse do Estado, da politics para a elaboração de public policies ${ }^{1}$. Os conselhos, portanto, funcionam sob a égide de alguns princípios como: o caráter público, a voz plural representativa da comunidade, a deliberação coletiva, a defesa dos interesses da cidadania e o sentido de pertencimento (BRASIL, 2004).

Sendo assim, os conselheiros necessitam aprofundar-se em estudos e investigações que os conduzam não simplesmente ao profissionalismo da função, ampliando os conhecimentos específicos da função e suas tarefas, descartando o amadorismo, diante do ordenamento jurídico que se impõe, mas preocupando-se em representar efetivamente a população, que deve dar-lhes recorrentes devolutivas sobre as ações desse colegiado. A ação dos conselheiros ocorrerá de acordo com as finalidades maiores da educação que a sociedade local espera, observando os objetivos do Estado de Direito, de forma a garantir limites do poder do Estado e a elevação da consciência e da participação dos cidadãos. Eis aqui a centralidade do papel dos Conselhos Municipais de Educação: possibilitar a

1 Sabe-se que as "politics" são fundamentais para a composição de um planejamento de políticas públicas, sem, no entanto, se confundirem com o seu processo de desenvolvimento, ou seja, enquanto nível de discussão nas distintas arenas, as politics antecedem as "public policies", caracterizando-se como espaço de poder onde distintos interesses e valores estão em recorrência. Nesse sentido, o discurso com maior apoio e influências na perspectiva dos demais atores constitui-se, de forma negociada, em pauta para uma possível agenda ou encaminhamento de negociações. As policies, por sua vez, podem ser caracterizadas como as atividades desenvolvidas pelo governo de um país ou de instâncias subnacionais no planejamento e desenvolvimento das políticas públicas. 
construção da consciência coletiva que por meio de decisões colegiadas estabelece o seu projeto e as suas expectativas de educação almejada.

Como recorte das políticas sociais, a educação precisa estar na agenda e nas discussões do que o município entende como prioridade. Aqui o município é muito mais do que um dos três poderes constituídos, isto é, inclui-se a participação da sociedade por meio de seus representantes, os cidadãos e cidadãs que devem posicionar-se de forma a defender as demandas educacionais comuns. O presente artigo discute o papel dos Conselhos Municipais da Educação e a sua ênfase na construção da consciência coletiva, ainda que em contextos adversos, visto as inclinações hegemônicas historicamente situadas, representada pelo controle social do executivo.

\section{Sobre as funções e responsabilidades do Conselho Municipal de Educação}

Muitas funções são igualmente importantes no Conselho Municipal de Educação (CME), como a consultiva e de assessoramento, e com especial destaque a função normativa, que se dá por meio de Pareceres ${ }^{2}$ e Resoluções ${ }^{3}$, que devem sempre ser compatíveis com as legislações das quais são decorrentes e principalmente com a que lhe dá o fundamento maior de validade: a Constituição Federal. A função normativa assessora a própria lei para atender os interesses coletivos de cidadania. Podemos dizer que tem uma função direta ao resguardar o direito à educação, e é indireta por não ter fundamento em si própria.

2 Um parecer é um ato enunciativo pelo qual um órgão emite um encaminhamento fundamentado sobre uma matéria de sua competência. Quando homologado por autoridade competente da administração pública ganha força vinculante.

3 A resolução é um ato normativo emanado de autoridade específica do poder executivo com competência em determinada matéria regulando-a com fundamento em lei. O Conselho Nacional de Educação, por lei, é um órgão com poderes específicos para expedir uma resolução (CURY, 2006, p. 43). 
E a tarefa normativa relativa à educação escolar, atribuída aos Conselhos de Educação, de modo a traduzir em atos a supremacia axiológica que emana da Constituição, não é recente. Eles possuem uma história a esse respeito que remonta, pelo menos, a proclamação da República (CURY, 2006, p. 44).

Os Conselhos Municipais de Educação contribuem de forma especial para que as leis sejam contextualizadas, regularizadas em seus aspectos institucionais e específicos, pois nenhuma lei é suficientemente capaz de fazê-lo por si só. Para tanto, este colegiado conta com a discrição como poder administrativo, entendendo por discrição a capacidade de distinguir, ou discernir. Esta permitirá ao administrador certa liberdade para definir a melhor maneira de respeitar a norma legal, ao mesmo tempo em que se observam as situações concretas daquele espaço social, concreto de experiências únicas.

Em decorrência desta condição Cury (2006), considera necessário destacar que o Conselho deve articular à sua legalidade a busca de uma legitimidade, e ainda acrescenta que o caminho do conselho deve ser trilhado com, pelo menos, três veios a fim de produzir normas que não possam ir além da lei: o do direito, o do estudo dos problemas educacionais e o da relação entre ambos. Neste sentido, este colegiado deve ter em sua composição membros capazes de zelar pelo cumprimento das leis e de assegurar a participação da sociedade no aperfeiçoamento da educação nacional. Os conselhos atuarão conforme demandas imperativas. Nesse contexto podem ser destacadas como principais competências a atuação sobre a criação, instalação de escolas de educação infantil da rede privada, quando for o caso, a aprovação de propostas pedagógicas, as equivalências de estudos, aprovação de regimentos escolares e outros. Porém, como destaca Cury (2006, p. 65):

[...] é, sobretudo, na consciência de guardião de direitos que o Conselho se articulará com as Secretarias de Educação, com os Conselhos Tutelares, com o Ministério Público e com outras instâncias de 
defesa dos direitos, além de seus homólogos municipais e estaduais e o Conselho Nacional de Educação.

Esse direito deve ser respeitado no interior do conselho de educação por seus conselheiros, agentes públicos de um serviço público, condição para que as atuais e novas gerações possam se beneficiar do acesso aos conhecimentos historicamente construídos, aos valores próprios dos direitos humanos e à cidadania. Com a mediação dos conselhos, Cury (2006) afirma que a educação se torna uma síntese entre igualdade e diferença. Mais do que meros executores de políticas, os cidadãos querem ser ouvidos nos momentos de elaboração das políticas públicas, assim como nos momentos de tomadas de decisão. A participação é a forma concreta da democracia. Mas, não qualquer participação. A participação que defendemos é aquela que se abre ao representante com direito de voz, vez e voto. Logo, há manifestação explícita da representatividade - não uma participação decorativa para validar decisões resolvidas e gabinetes somente para serem chanceladas no espaço público, mas uma participação de fato, uma vez que a vida social e seus interesses são objetos centrais.

No que tange ao CME, o olhar sobre a coisa pública tem que ser objeto de conscientização de todos os participantes. Não basta querer apenas compor numericamente o colegiado; cada conselheiro deve se apropriar do seu papel, das ações que devem e têm que tomar como suas prioridades, visto que não mais se admitem papéis passivos que nenhum impacto causam no cotidiano do cidadão.

\section{O Conselho Municipal de Educação: participação, autonomia e qualidade socialmente referenciada}

Amplamente disseminados entre as décadas de 1980 e 1990, os conselhos gestores surgem a partir dos movimentos que buscaram estratégias para concretizar a participação da sociedade civil nos procedimentos burocráticos do Estado. A partir de então, estes conselhos constituíram-se em espaços de debates e embates entre o Estado e a sociedade civil, delineados e 
embasados por uma concepção democrática onde a participação do cidadão nas políticas públicas é compreendida como direito político.

Esta forma de participação traz como consequências modificações na noção de cidadania, ao imprimir outras significações e sentidos, saindo da compreensão de que a cidadania se reduz apenas ao ato de participação através do voto - participação indireta na escolha de representantes passando a incorporar e abranger a ideia de participação direta, ou seja, de tomar parte na elaboração e na definição de políticas públicas, assim como no direito de acompanhar e fiscalizar suas execuções - o direito a ter direitos (ELIAS, 2008, p. 30).

O grande desafio para a consolidação ou mesmo para o desenvolvimento do movimento democrático é a promoção da participação dos cidadãos na compreensão de seu papel e vigilância de seu contexto social. A participação é um dos mais importantes princípios políticos e implica a criação de formas de escuta do governo quanto às opiniões da sociedade civil. Para além de ouvi-las, cabe também considerá-las nos momentos das formulações, deliberações e implementações das políticas públicas.

A vigilância sobre o controle social se faz necessária para uma melhor validação dos anseios populares por meio de sua participação, pois amplia o acesso à informação, envolve monitoramento dos poderes públicos e a transparência de forma geral, visando o benefício de toda a sociedade. A participação evidencia um ideal democrático que:

Supõe cidadãos atentos à evolução da coisa pública, informados dos acontecimentos políticos, ao corrente dos principais problemas, capazes de escolher entre as diversas alternativas apresentadas pelas forças políticas e fortemente interessados em formas diretas ou indiretas de participação (BOBBIO, 1986, p. 89).

Para Elias (2008, p. 61), a participação pode ser entendida a partir das seguintes distinções conceituais: 
- Participação Liberal — dados os pressupostos básicos do liberalismo, objetiva o fortalecimento da sociedade civil, não para que esta participe da vida do Estado, mas para fortalecê-la e evitar as ingerências do poder público. Baseia-se no princípio da igualdade no qual a participação permite a busca pela satisfação das necessidades;

- Participação Corporativa - advém do sentimento de concordância e identidade da existência de um bem comum, extrapolando os interesses individuais. O processo participativo está vinculado à existência de organizações na sociedade;

- Participação Comunitária - é uma forma institucionalizada de integração através de órgãos representativos da sociedade, aos órgãos deliberativos e administrativos do Estado;

- Participação Autoritária - orientada para a integração e controle social da sociedade e da política, geralmente em regimes políticos autoritários. Em regime democrático age-se de forma cooptativa, na qual a promoção de políticas públicas é um exemplo de estímulo verticalizado (de cima para baixo) apenas com intuito de diluir os conflitos sociais;

- Participação Democrática - a participação deriva das ações tanto na esfera civil quanto política, de maneira institucional e bem delimitada. Opõe-se ao modelo corporativista e se sustenta no modelo representativo;

- Participação Revolucionária - estrutura-se em grupos organizados para lutar contra as relações de dominação e de divisão do poder político. O sistema partidário é uma exemplificação desse modelo;

- Participação Radical - engloba teóricos e ativistas que questionam e buscam a substituição do modelo representativo por outro onde o poder fique nas mãos da comunidade, com redistribuição de poder. Busca o fortalecimento da sociedade civil para delinear outra realidade, com justiça social.

A questão básica que se coloca, de acordo com Teixeira (2001, p. 27), é a de valorizar todas as possibilidades de participação, para fortalecer e aprofundar a democracia, ou perceber seus limites, observando que participação outorgada não é entendida como participação, mas ordenamento de uma ação que favorece o controle social por meio dos detentores de poder. Efetivamente, a participação supõe uma relação de poder, não só por intermédio do Estado, que a materializa, mas entre os 
próprios atores, exigindo determinados procedimentos e comportamentos racionais que estabeleçam os parâmetros necessários para garantia e respeito ao direito de todos, além das aspirações da sociedade.

Os conselhos, de forma geral, dependem financeiramente da administração municipal, portanto sua autonomia é um tanto quanto polêmica e coloca o seu funcionamento imerso em tensões. Os recursos nem sempre são destinados no prazo e na quantia e/ou quantidades necessárias, mesmo fazendo parte do orçamento das Secretarias responsáveis, portanto o espaço de discussão recorrente e dialética na condução dos interesses dos cidadãos, por conta dos conselheiros, deve estar assentado em uma base de diplomacia e reivindicação. Diplomacia por fazer valer a leitura sobre o conceito e dimensão dos segmentos representados, e reivindicação por atuar de forma efetiva por apresentar, agendar, promover o enfrentamento quanto à não supressão das conquistas históricas dos munícipes, assim:

[...] é fundamental que os conselhos tenham autonomia para propor e deliberar sobre questões de sua esfera de competência legal e que o executivo não possa deliberar, nem adotar, em matéria definida em lei como de competência do conselho, ações que contrariam decisões deste. Caso o executivo considere inviável ou inadequado adotar a decisão do conselho, deve solicitar a reanálise do assunto, oferecendo razões fundamentadas. Mas é imperioso distinguir quais decisões do conselho devem ser objeto de homologação e quais não necessitam dela (BORDIGNON, 2009, p. 21).

Podemos assim dizer que a legislação instituidora do CME deve ser clara e abranger as competências, funções, organização estrutural e composição, o que oportunizará o exercício do direito democrático e atuação dos conselheiros, evidenciando o grau de autonomia na proposição, enfrentamentos e luta pela consolidação dos interesses dos cidadãos:

As condições de funcionamento do conselho indicam o grau de autonomia e sua importância na gestão do sistema de ensino. A autonomia requer que o conselho seja dotado de normas próprias e condições 
objetivas para desempenhar suas responsabilidades. Sem condições de exercer suas funções com autonomia, dependentes da boa vontade do executivo para funcionar, os conselhos ficariam desprovidos de sua natureza de órgãos de Estado (BORDIGNON, 2010, p. 22).

Ainda que a legislação determine os limites de atuação do conselho, o fator de determinação e validação de suas decisões, assim como a participação social determinam o grau de gestão democrática do país nos conselhos e órgão colegiados - como é o caso do foco desse trabalho, o Conselho Municipal de Educação. Acredita-se que políticas públicas formuladas e implementadas pelos próprios municípios atendam melhor as necessidades e a diversidade da população local, apontando para a descentralização, de forma que a sociedade civil local possa acompanhar e avaliá-las melhor.

Esta forma de atuação, no entanto, depende de para quem o município está trabalhando, se para a população local ou para o poder a que se submete. Nessa ênfase destaca-se que o poder local é mais abrangente que o governo local, de modo a interferir nas políticas públicas, pois adentra o governo local. O local ganha espaço a partir de 1990, e passa a ser visto como espaço de gestão político-administrativo. Novas formas participativas ocorrem nos governos locais tendo o empenho popular na construção de conhecimentos e elaboração de formas para solucionar problemas e conflitos:

A qualidade da participação pode ser mensurada pelo grau de informação (ou de desinformação) contido nas opiniões dos participantes. Assim como os movimentos sociais dos anos 1970/80, os novos experimentos participativos desempenham também um papel educativo entre seus participantes, à medida que fornecem informações, capacitamos à tomada de decisões e desenvolvem uma sabedoria política. Eles contribuem para o desenvolvimento de competências e habilidades a partir das experiências que vivenciam. Nesse sentido contribuem para o desenvolvimento político dos indivíduos (GOHN, 2002, p. 20).

Os conselhos, neste sentido, aparecem como resposta das demandas populares e pressão da sociedade civil na busca pela redemocratização do país. Definidos na Constituição de 1988 como espaços de representação e expressão da sociedade civil, inserem-se na esfera pública, vinculam-se 
ao Executivo e necessitam assessorar as áreas em que atuam pelo viés da representatividade dos interesses do município. A participação efetiva pode garantir o direito a educação de qualidade a partir dos conselhos, uma vez que, ligada à paridade e a representatividade dos membros, irão compor este espaço de gestão. De nada adianta a perspectiva de uma educação socialmente referenciada se não ocorrer uma participação popular diversificada neste colegiado de gestão da educação. Na verdade, a educação somente será socialmente referenciada se construída pelos cidadãos.

Para Borges (2017), a inserção do termo "socialmente referenciada" à categoria qualidade é expressa pela necessidade de se pensar em uma educação que prime pela formação humana, consciente das contradições e batalhadora no sentido de superá-las. A qualidade educacional não deve se limitar a aspectos quantitativos, ou então sem prescindir desses deve colocar como centralidade os interesses contextuais dos cidadãos e a sua busca pela consolidação do viver social centrado na justiça e dignidade humana.

No campo educacional os CMEs se expandem a partir da CF/1988, a qual institui a gestão democrática do ensino público, prevista no Artigo 206, inciso VI, como um dos princípios básicos da educação. No viés democrático, esse princípio pressupõe a participação da sociedade nas definições que serão tomadas no campo educacional e passa a requerer dos CMEs um novo perfil de competências ligadas não só às questões normativas, mas também às de controle e mobilização social (SILVA, 2013, p. 53).

Portanto, tanto a participação como as formas propostas para que ocorram caracterizarão ou não formas de ação de gestão democrática, e a busca pelo que se chama de expectativas da comunidade e sociedade sobre a qualidade da educação ou simplesmente "qualidade socialmente referenciada".

Para além deste fato, o Programa Nacional de Fortalecimento dos Conselhos Escolares (BRASIL, 2006, p. 10) destaca que todas as pessoas têm direito subjetivo à educação de qualidade socialmente referenciada. $\mathrm{A}$ este direito corresponde a obrigação da oferta de condições objetivas para que cada cidadão se construa autônomo, livre e responsável. Tal dever é do Estado, da família e da sociedade como um todo. Portanto, todos os 
cidadãos e cidadãs têm o direito e o dever de contribuir para ampliar e garantir a qualidade da prática educativa escolar e a inclusão universal.

\section{A relevância do Conselho Municipal de Educação na vida da coletividade}

A vida coletiva implica situações complexas cujas peculiaridades imponderáveis não podem ser previstas, necessitando dessa flexibilidade e abertura que um órgão como o Conselho de Educação pode permitir. A vida coletiva não é um automatismo previsível. Como afirma Di Pietro (2004, p. 206):

Sob o ponto de vista prático, a discricionaridade justifica-se, quer para evitar o automatismo que ocorreria fatalmente se os agentes administrativos não tivessem senão que aplicar rigorosamente as normas preestabelecidas quer para suprir a impossibilidade em que se encontra o legislador de prever todas as situações possíveis que o administrador terá de enfrentar, isto sem falar que a discricionaridade é indispensável para permitir o poder de iniciativa da Administração, necessário para atender às infinitas, complexas e sempre crescentes necessidades coletivas. A dinâmica do interesse público exige flexibilidade de atuação, com a qual pode revelar-se incompatível o moroso procedimento de elaboração das leis.

Teixeira (2004) afirma que os Conselhos Municipais de Educação são canais que legitimam a gestão democrática à luz da Constituição e da LDBEN, logo o termo participação não deve ser utilizado como mais uma palavra do discurso político, mas como uma que determine as ações e deliberações coletivas, legitimando as expectativas do que a população defende como necessário e recorrente.

Souza e Vasconcelos (2006) enfatizam que os diversos segmentos da sociedade devem estar contemplados na constituição do Conselho juntamente com membros do poder público, garantindo um possível equilíbrio numérico das forças colegiadas, porém destaca que o controle social 
da educação não está garantido apenas pela existência legal dos conselhos, mas pela qualidade das discussões e práticas do colegiado, que a partir da leitura do seu real pode ressignificá-lo substancialmente. Bordingnon (2009; 2010) amplia a visão e orienta que um CME que dialoga e busca representar efetivamente os munícipes tem condições de contribuir efetivamente não somente para a construção do Plano Municipal de Educação, mas na pontuação de prioridades que poderão melhor atender ao direito educacional em sua oferta, condições e distribuição de recursos. Cury (2006) observa que, diante das leis e normativas do país, do direito constitucional da cidadania, a relevância da formação dos conselheiros para ações democráticas deve evidenciar-se e garantir espaços colegiados como canais efetivos de participação. Lima, Aranda e Lima (2012) ampliam o entendimento a respeito de participação como canal de processo democrático e gestão democrática.

Toda esta estrutura visa garantir a participação dos diversos segmentos da sociedade neste espaço de consultas, normativas, indicações e de deliberações, que busca garantir incessantemente a qualidade da Educação. Porém, mesmo em face de uma necessária paridade entre os representantes do poder público e da sociedade civil na composição dos CMEs, é importante observar que tal repartição, na prática, significa apenas um possível equilíbrio numérico de forças colegiadas, não devendo ser tomada como garantia da prevalência ou da hegemonia de interesses sociais mais amplos sobre os privados, especialmente, no âmbito das atribuições que aqui sobressaíram como as mais importantes exercidas nesses Conselhos: as de caráter deliberativo e normativo (VASCONCELOS, 2003).

Nas ponderações de Silva (2013) isso significa que os Conselhos Municipais de Educação (CMEs) não devem receber passivamente as informações das políticas educacionais em andamento e nem se deter em sua mera discussão, mas antes atuar de forma ativa na sua construção, por meio da tomada de decisões e de ações que impliquem políticas educacionais democratizantes em todos os níveis e modalidades de ensino, 
questionando sobre qual educação está implantada e qual a que se quer implantar, em uma visão estrutural, política, histórica e transformadora.

Para Cury (2006, p. 58), os cidadãos querem mais do que ser executores de políticas; querem ser ouvidos em arenas públicas de elaboração e nos momentos de tomada de decisão. Trata-se de democratizar a própria democracia pela participação. Tal é o caso dos múltiplos Conselhos hoje existentes no âmbito de controle e fiscalização de recursos obrigatórios para a educação escolar, da merenda e de outros assuntos. Tal é o caso também dos orçamentos participativos em diversos municípios do país. É neste sentido que a gestão democrática é um princípio constituinte dos Conselhos de Educação.

\section{Os Conselhos Municipais de Educação e a gestão democrática}

O artigo 204, Incisos I e II da Constituição Federal do Brasil (BRASIL, 1988), no tocante ao atendimento de demandas sociais, enfatiza: a) a descentralização político-administrativa, com atribuições específicas da União quanto à coordenação e às normas gerais e "a coordenação e a execução dos respectivos programas às esferas estadual e municipal”; b) a "participação da população, por meio de organizações representativas, na formulação das políticas e no controle das ações em todos os níveis".

Os processos participativos e democráticos se consolidam à medida em que sejam discutidos e transformados em objetos em movimento, resguardando-se o princípio da soberania cidadã e sua recorrência como direito que se aperfeiçoa conforme o seu respectivo direito. Como princípio orientador, a cidadania deve ser mobilizada por processos participativos, regulados por lei, como acima destacado. Assim, a busca por sua legitimação deve ocorrer por canais que promovam e garantam a consolidação democrática em distintas esferas de responsabilidade.

De forma recortada, a partir da Constituição de 1988, a normatização e a emancipação conferidas pelos municípios como entes federativos esboçavam caminhos de participação do poder local e, com eles, a 
responsabilidade de assumir as políticas públicas conforme a instituição do processo de municipalização e, no caso da educação, articulando-se com a criação dos Conselhos Municipais de Educação. Os CMEs como órgãos mediadores entre a sociedade civil organizada e os organismos governamentais assumem importante influência no poder local acerca do controle social no âmbito da educação, considerando o seu comprometimento com as demandas sociais e fortalecimento dos sujeitos na consolidação dos direitos dos munícipes. De acordo com Gohn (2007, p. 107-108):

Os conselhos são instrumentos de determinados processos políticos e constituem inovações institucionais na gestão de políticas sociais no Brasil. Esses processos podem ter diferentes objetivos, contribuir para mudanças sociais significativas ou auxiliar a consolidação de estruturas sociais em transição ou sob o impacto de fortes pressões sociais.

[...] dependendo como são compostos, poderão eliminar os efeitos do empowerment, do sentido de pertencer dos indivíduos, e reafirmar antigas práticas herdeiras do fisiologismo. Como tal, carregam contradições e contrariedades. Tanto podem alavancar o processo de participação sociopolítica de grupos organizados, como estagnar o sentimento de pertencer de outros - se monopolizados por indivíduos que não representem, de fato, as comunidades que os indicaram/elegeram.

O desenvolvimento do papel dos CMEs à luz da gestão democrática deve deixar claro o critério de paridade e da representatividade, ou seja, ao serem estabelecidas as garantias sobre a consistente igualdade em número e condições dos participantes se irá buscar a transparência sobre o exercício plural da própria sociedade e o exercício da cidadania. É necessário que haja clareza sobre a duração do mandato de cada conselheiro e sua recondução, quando for o caso, evitando-se cooptações ou algo semelhante; mais do que isso, cabe ao Conselheiro ter compromisso com a comunidade que representa (GOHN, 2006, p. 9). A gestão democrática, princípio transversal às ações dos CMEs, é entendida como processo de: 
[...] trocas, intercâmbios de ideias realizáveis ou por se realizarem, ou mesmo articulações que expressem o posicionamento do grupo, podendo ou não se convergir para a ação; dentro de uma organização social legitimamente constituída, onde os indivíduos participam ativamente na tomada de decisões, interatuando dialeticamente com seus pares e abertos à interação com diferentes grupos [...] a fim de que os parâmetros estabelecidos dentro do trâmite consensual e os objetivos dos grupos alcançados ou encaminhados para aprimoramento e projeções sejam trabalhados ou mesmo, se inviáveis sejam feitas reconsiderações, dado ao seu grau de validade ou não para o contexto que determinada realidade solicita (LIMA, 2013, p. 13).

A conscientização crítico-reflexiva não acontece de maneira linear ou mesmo por concessão, pois surge nos movimentos democratizantes contra-hegemônicos - portanto, num espaço coletivo em que os indivíduos não mais concedem a terceiros a deliberação de suas necessidades ou planificação de suas realidades, pois eles mesmos se constituem protagonistas de sua ação e leitura de mundo, logo, são sujeitos históricos que se reconhecem como tais e atuam no movimento da história (LIMA, 2013). Não é a instituição do CME que confere a autorização para se buscar a educação que se deseja, como afirmam Lima, Aranda e Lima (2012, p. 57):

Pensar que a gestão democrática é obra de lideranças bem intencionadas é acreditar em uma forma autocrática de democracia, na qual seus postulados estão hierarquizados, padronizados, organizados e dirigidos. A gestão democrática inclui, em si, postulados conflituais. Ou seja, a gestão democrática não pode ser reduzida a uma dimensão instituída, ela é, sempre instituinte e instituída. Decorre daí os seus princípios: descentralização, participação e autonomia. Tais princípios são basilares para a concretização da democratização, o que indica, uma relação de poder, a socialização do poder, a participação no poder. Descentralização só se realiza pelos elementos instituintes e instituídos: participação e autonomia.

Aprender sobre e atuar de forma a referendar a consciência coletiva deve ser o papel de cada um dos conselheiros. Como afirma Lima (2007, 
p. 71), a consciência coletiva aprimora a percepção dos sujeitos na busca pelos interesses e objetivos comuns. O espaço democrático deverá ser onde se produz a autoprodução de cada ator e das demandas que os cercam. Assim "[...] as solicitações são analisadas em profundidade e a participação se materializa por meio do exercício do direito de vez, voz e voto".

\section{Considerações finais}

Mais do que um local para discussão coletiva para definição dos interesses e objetivos da comunidade municipal, os Conselhos Municipais de Educação são agências de formação da consciência coletiva. A consciência coletiva se faz para apropriação do contexto e autoprodução do ator social à medida que, não se deixando conduzir por métricas instituídas, as questiona e orienta suas expectativas e mobilizações instituintes para o "valor" instituinte, isto é, respostas às questões - sobre quais parâmetros se deseja a educação socialmente referenciada? que prioridades devem ser objeto de escolha para melhoria da qualidade educacional do município? visto a composição de uma agenda variada entre as propostas do Executivo, as normativas nacionais e as necessidades municipais, o que deve ter centralidade, considerando os recursos escassos?

Saber quem são os representantes da população no CME tem suma importância dentre pais, professores, representantes do executivo, estudantes, entidades sociais, etc. E por quê? Para saber que prioridades têm sido colocadas na agenda do município e quais interesses são objeto de centralidade. Para além disso, para saber como se está processando o espaço democrático da participação e se a representatividade no CME de fato reflete o que a população entende e deseja para a educação do município.

A participação por meio do CME pode conferir aos representantes, como destacamos no corpo do texto, a construção da consciência coletiva, rompendo-se com a lógica da fragmentação ou representação reducionista dos segmentos sociais. É a partir da consciência coletiva que surgem e são encaminhados os seguintes questionamentos: quem 
somos? onde estamos e qual é a finalidade do desenvolvimento do nosso trabalho? a quem servimos e como aperfeiçoar a nossa ação interventiva de forma a promover a melhoria de qualidade da educação em nosso município? como nos posicionamos politicamente frente as crises do mundo contemporâneo e por meio de seus condicionantes provocamos a crítica-reflexiva? em que grau e em que medida o nosso trabalho infere para a melhoria efetiva da educação que queremos e de que precisamos?

Marx e Engels (1987, p. 25-26) vão afirmar que a "[...] produção de idéias, de representações e da consciência está em primeiro lugar direta e intimamente ligada à atividade material e ao comércio material dos homens; é a linguagem da vida real [...]". Consequentemente a vida determina a consciência das relações. Desta construção, as ideias produzidas pelo homem referem-se à sua atuação sobre o mundo vivido, constituindo-se na organização do conhecimento humano como produto de múltiplas determinações.

Portanto, as múltiplas determinações sempre se dão no espaço que é, necessariamente, político, e por meio da gestação de interesses numa dimensão ampla ou restrita são construídas as ideologias pertinentes (LIMA, 2011). O desdobramento do trabalho do CME, por meio de planificação e representatividade, não deve deixar de considerar esta visão sobre o fenômeno educacional mediada pelas múltiplas vozes que compõem o seu contexto e entorno; caso contrário, concorrerá para o velamento da realidade e ênfase dos anseios de uma sociedade alienadora e alienante.

\section{Referências}

BOBBIO, N. O futuro da democracia: uma defesa das regras do jogo. Rio de Janeiro: Paz e Terra, 1986.

BORDINGNON, G. Gestão da educação no município: sistema, conselho e plano. São Paulo: Editora e Livraria Instituto Paulo Freire, 2009. 
BORDINGNON, G. Passos para criar um Conselho: Conselho Municipal de Educação: colegiado da gestão democrática do Sistema. Brasília: UNCME, 2010. Disponível em: <http://www.uncme.com.br/principal/exibir_conteudo.asp?CO_ AREA=7>. Acesso em: 9 dez. 2010.

BORGES, G. S. Direito a educação e a qualidade socialmente referenciada do ensino: a atuação do CME de Mineiros/GO. Dissertação (Mestrado em Educação) Universidade Federal de Goiás, Goiânia, 2017. Disponível em: <http://repositorio.bc.ufg.br/tede/handle/tede/6896 >. Acesso em: 20 jul. 2017.

BRASIL. Constituição da República Federativa do Brasil. Brasília: Senado, 1988.

BRASIL. Ministério da Educação e Cultura. Programa Nacional de Fortalecimento dos Conselhos Escolares. Brasília: Portal Mec, 2006. Disponível em: <http://portal.mec.gov. br/pec-g/195-secretarias-112877938/seb-educacao-basica-2007048997/12619publicacoes-dos-conselhos-escolares >. Acesso em: 20 jul. 2017.

BRASIL. Presidência da República. Lei no 9394, de 20 de dezembro de 1996 (Lei de Diretrizes e Bases da Educação Nacional). Estabelece as diretrizes e bases da educação nacional. Brasília: [s.n.], 1996.

BRASIL. Ministério da Educação. Secretaria de Educação Básica. Conselhos Escolares: uma estratégia de gestão democrática da educação pública. Brasília: Portal Mec, 2004. Disponível em: <http://portal.mec.gov.br/seb/arquivos/pdf/ Consescol/ce_gen.pdf $>$. Acesso em: 20 jul. 2017.

CURY, C. R. J. Gestão democrática da educação: exigências e desafios. Revista Brasileira de Política e Administração da Educação, v. 18, n. 2, jul./dez. 2002. Disponível em: <http:// www.seer.ufrgs.br/rbpae/article/viewFile/25486/14810>. Acesso em: 12 mar. 2017.

CURY, C. R. J. Conselhos escolares: uma estratégia de gestão democrática na escola pública. Ministério da Educação e Cultura. Secretaria da Educação Básica. Brasília: [s.n.], 2004. p. 35-40.

CURY, C. R. J. Conselhos de educação: fundamentos e funções. Revista Brasileira de Política e Administração da Educação, v. 22, n. 1, p. 41-67, fev. 2006. Disponível em: <http://seer. ufrgs.br/index.php/rbpae/article/view/18721/10944>. Acesso em: 12 mar. 2017. 
DI PIETRO, M. S. Z. Direito Administrativo. São Paulo: Atlas, 2004.

ELIAS, L. G. D. E. O conselho municipal de educação: a participação da sociedade civil e os desafios da representação democrática nas deliberações das políticas educacionais para o município de Belém-PA. Dissertação (Mestrado em Educação) - Universidade Federal do Pará, Belém, 2008. Disponível em: <http://www.repositorio.ufpa.br:8080/jspui/handle/2011/1719 >. Acesso em: 10 jul. 2017.

GOHN, M. G. Conselhos gestores na política social urbana e participação popular. Cadernos Metrópole, n. 7, p. 9-31, $1^{\circ}$ sem. 2002. Disponível em: <https://revistas.pucsp. br/index.php/metropole/article/download/9257/6867>. Acesso em: 10 jul.2017.

GOHN, M. G. Educação não-formal, participação da sociedade civil e estruturas colegiadas nas escolas. Ensaio: avaliação e políticas públicas em educação, Rio de Janeiro, v. 14, n. 50, p. 27-38, jan./mar. 2006. Disponível em: <http://escoladegestores.mec.gov.br/site/8-biblioteca/pdf/30405.pdf >. Acesso em: 10 jul. 2017.

GOHN, M. G. Conselhos gestores e participação sociopolítica. 3. ed. São Paulo: Cortez Ed, 2007.

LIMA, P. G. Saberes pedagógicos da educação contemporânea. Engenheiro Coelho: UNASPRESS, 2007.

LIMA, P. G. Ação-reflexão-ação no processo de formação continuada de professores: desafios à organização do trabalho coletivo. Revista de la Escuela de Ciencias de la Educación, n. 6, p. 41-56, 2011. Disponível em: <http://www.revistacseducacion.unr.edu.ar/ojs/ index.php/educacion/article/download/27/26>. Acesso em: 9 maio 2018.

LIMA, P. G. Temas em Políticas e Gestão da Educação. Dourados: Editora da UFGD, 2013.

LIMA, P. G.; ARANDA, M. A. M.; LIMA, A. B. Políticas educacionais, participação e gestão democrática da escola contemporânea brasileira. Rev. Ensaio, Belo Horizonte, v. 14, n. 1, p. 51-64, jan./abr. 2012. Disponível em: <http://www.scielo. br/pdf/epec/v14n1/1983-2117-epec-14-01-00051.pdf 〉. Acesso em: 9 maio 2018. MARX, K.; ENGELS, F. A ideologia alemã (Feuerbach). 6. ed. São Paulo: Hucitec, 1987. 
SILVA, M. A. C. Conselho Municipal de Educação de Uberlândia-MG: possibilidades na Democratização da Educação Municipal (2009-2012). Uberlândia: [s.n.], 2013.

SOUZA, D. B.; VASCONCELOS, M. C. C. Os Conselhos Municipais de Educação no Brasil: um balanço das referências nacionais (1996-2002). Ensaio: avaliação e políticas públicas em educação, Rio de Janeiro, v. 14, n. 50, p. 39-51, jan./mar. 2006.

TEIXEIRA, E. O poder local e o global: limites e desafios da participação cidadã. São Paulo: Cortez; Recife: EQUIP; Salvador: UFBA, 2001. Disponível em: <http:// www.bibliotecadigital.abong.org.br/bitstream/handle/11465/1744/252. pdf? sequence=1\&isAllowed=y > . Acesso em: 12 jun. 2017.

TEIXEIRA, L. H. Conselhos municipais de educação: autonomia e democratização do ensino. Cadernos de Pesquisa, v. 34, n. 123, p. 691-708, set./dez. 2004. Disponível em: <http://www.scielo.br/pdf/cp/v34n123/a09v34123.pdf〉. Acesso em: 12 jun. 2017.

VASCONCELOS, M. C. C. Conselhos Municipais de Educação: criação e implantação em face das novas atribuições dos sistemas municipais de ensino. Desafios da educação municipal. Rio de Janeiro: DP\&A, 2003.

Recebido: 03/04/2018

Received: 04/03/2018

Recibido: 03/04/2018

Aprovado: 25/05/2018 Approved: 05/25/2018 Aprobado: 25/05/2018 